\title{
Effect of Draw Blank Velocity on Steel Fluid Flow Field in Blank Continuous Caster Crystallizer
}

\author{
Zening $\mathrm{Xu}^{1, \mathrm{a}}$,Hongyu Liu ${ }^{1, \mathrm{~b}}$, Yanping $\mathrm{Lu}^{1, \mathrm{c}}$ and Leigang $\mathrm{Liu}^{2}$ \\ ${ }^{1}$ Liaoning University of Science and Technology, Anshan, Liaoning114051, China \\ ${ }^{2}$ The wire factory of Anshan Iron and Steel company stock,Anshan,Liaoning,China \\ axuzening-1@163.com, 'Ihy_04@126.com, 'xingyun27@126.com
}

\begin{abstract}
Keywords: blank continuous caster; crystallizer; draw blank velocity; flow field; numerical simulation analysis
\end{abstract}

\begin{abstract}
As the heart of continuous caster, crystallizer is the cradle of most surface deficiencies and inside quality problems in steel blank. Steel blank surface quality, nonmetal impurity content and relevant distribution rely on the steel fluid solidification behavior namely steel fluid flow field distribution on great extent. For the high temperature steel fluid has big kinetic energy, so, the immixture dregs, solidification heat conduction, temperature field distribution in crystallizer, solidification blank shell thickness distribution and continuous caster blank quality were influenced by steel fluid flow. The numerical simulation analysis on flow field and temperature field in crystallizer were conducted in this paper. Three dimensions turbulent flow model was adopted to computate flow field. The heat conduction was ignored on draw blank direction in temperature field. The conjugate heat conduction model of ANSYS CFX was adopted to analyze temperature field, which can consider heat conduction in solid layer and convection heat conduction between solid shell face and fluid simultaneity. The draw blank velocity was found by setting crystallizer water gap insertion depth and crystallizer water gap angle, which can obtain reasonable flow field in blank crystallizer.
\end{abstract}

\section{Intorduction}

The first problem for analyzing temperature field distribution in continuous caster crystallizer is steel fluid flow. It was influenced by impurity float in steel fluid and steel fluid protection dregs immixture. Reasonable flow field distribution is benefit to impurity float in steel fluid and prevention dregs immixture ${ }^{[1]}$. The original blank shell and steel fluid temperature distribution in blank shell was influenced by steel fluid flow in crystallizer. Reasonable flow field distribution can increase the homogenization of original blank shell, decrease steel fluid underwashing on blank shell and prevent temperature field from increasing steel fluid temperature too high in blank shell. 


\section{Basic parameters and theory}

The basic parameters of blank continuous caster crystallizer. The basic parameters of blank continuous caster crystallizer were shown in table 1.

Table 1 Basic parametesrs of blank continuous caster crystallizer

\begin{tabular}{|c|c|c|c|}
\hline Blank thichness(mm) & 150 & teeming temperature $\left({ }^{\circ} \mathrm{C}\right)$ & 1515 \\
\hline blank width(mm) & 1000 & liquidus temperature $\left({ }^{\circ} \mathrm{C}\right)$ & 31 \\
\hline Metallurgy length(m) & 22.4 & steel fluid heat conduction coefficient $(\mathrm{W} / \mathrm{m} \cdot \mathrm{K})$ & 650 \\
\hline Effective crystallizer length $(\mathrm{mm})$ & 1000 & steel fluid specific heat $(\mathrm{J} / \mathrm{kg} \cdot \mathrm{K})$ & 270 \\
\hline immersion water gap depth(mm) & $110-160$ & solidification latent heat $(\mathrm{KJ} / \mathrm{kg})$ & 1.6 \\
\hline immersion water gap angle & $20^{\circ}$ & draw blank velocity $(\mathrm{m} / \mathrm{min})$ & 7020 \\
\hline crystallizer conical degree & $1.1 \%$ & steel fluid density $\left(\mathrm{Kg} / \mathrm{m}^{3}\right)$ & 0.0062 \\
\hline steel fluid entrance velocity(t/min) & $1.5-3$ & steel fluid viscosity $(\mathrm{Kg} / \mathrm{m} \cdot \mathrm{s})$ & \\
\hline
\end{tabular}

The linking research of flow and heat conduction phenomenon was conducted by ANSYS CFX. The both side hole and downward obliquity immersion water gap was adopted, which is shown in Fig. $1^{[2]}$.

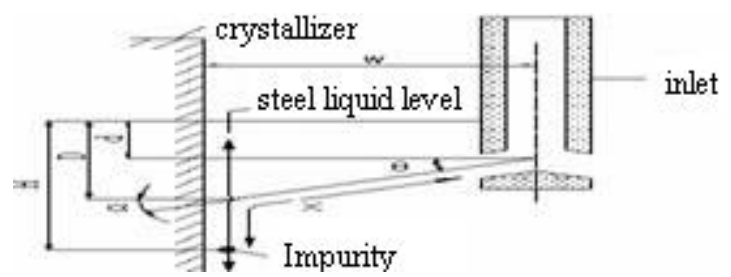

Fig.1 Sketch map of liquid flow on insertion water gap

\section{Basic hypothesis of model}

The solidification shell in crystallizer was ignored. Steel fluid was treated as homogeneous phase medium. The influence of curved face fluctuation was ignored. The vibration influence on flow was ignored. The steel fluid gravity influence was ignored. Steel fluid flow was driven by initial velocity on water gap exit ${ }^{[3]}$.

\section{Governing equation}

The governing equation of steel fluid flow may be shown as:

(1) Mass conservation equation:

$$
\frac{\partial\left(\rho u_{i}\right)}{\partial x_{j}}=0
$$

(2) Momentum equation:

$$
\rho \frac{\partial\left(u_{i} u_{j}\right)}{\partial x_{j}}=\frac{\partial p}{\partial x_{i}}+\frac{\partial}{\partial x_{j}}\left(\mu_{e} \frac{\partial u_{i}}{\partial x_{j}}\right)+\frac{\partial}{\partial x_{i}}\left(\mu_{e} \frac{\partial u_{j}}{\partial x_{i}}\right)+\rho g_{i}
$$


(3)Turbulency kinetic energy equation:

$\rho \frac{\partial u_{i} k}{\partial x_{i}}=\frac{\partial}{\partial x_{i}}\left[\left(\mu_{e}+\frac{\mu_{t}}{\sigma_{k}}\right) \frac{\partial k}{\partial x_{i}}\right]+G-\rho \varepsilon$

(4) Turbulency kinetic energy dissipation equation:

$$
\begin{aligned}
& \rho \frac{\partial\left(u_{i} \varepsilon\right)}{\partial x_{i}}=\frac{\partial}{\partial x_{i}}\left[\left(\mu_{e}+\frac{\mu_{t}}{\sigma_{e}}\right) \frac{\partial \varepsilon}{\partial x_{i}}\right]+c_{1} \frac{\varepsilon}{k} G-c_{2} \varepsilon \\
& G=\mu_{t} \frac{\partial u_{j}}{\partial x_{i}}\left(\frac{\partial u_{i}}{\partial x_{j}}+\frac{\partial u_{j}}{\partial x_{i}}\right) . \\
& \mu_{e}=\mu+\mu_{t}=\mu+\rho c_{\mu} \frac{k^{2}}{\varepsilon} .
\end{aligned}
$$

Among above equation, $\mathrm{ui}$ are velocity on $\mathrm{X}$-axis, $\mathrm{Y}$-axis and $\mathrm{Z}$-axis separately namely $\mathrm{uX}, \mathrm{uY}$, and $\mathrm{uZ}$, in which $\mathrm{i}$ take 1,2 and $3 . \mathrm{K}$ is turbulency kinetic energy. $\varepsilon$ is turbulency kinetic energy dissipation ratio. Correlation coefficient were chosen according to recommended data. $\mathrm{C} 1$ is $1.44, \mathrm{C} 2$ is $1.92, C_{\mu}$ is $0.09, \sigma_{k}$ is $1.0, \sigma_{\varepsilon}$ is 1.3 .

\section{Boundary conditions treatment}

Relevant boundary conditions must be required in solving Eq.1 to Eq.6. Considering the characteristic of continuous caster crystallizer, in-built model computation boundary conditions of CFX were given as follows:

(1) On crystallizer free fluid surface, Eq.7 must be satisfied.

$$
\frac{\partial u_{x}}{\partial z}=\frac{\partial u_{y}}{\partial z}=\frac{\partial k}{\partial z}=\frac{\partial \varepsilon}{\partial z}=u_{z}=0
$$

(2) On crystallizer symmetry center surface X-Z, Y-Z and normal direction Eq.8 and Eq.9 must be satisfied.

$$
\begin{aligned}
& \frac{\partial u_{x}}{\partial y}=\frac{\partial u_{y}}{\partial y}=\frac{\partial k}{\partial y}=\frac{\partial \varepsilon}{\partial y}=u_{y}=0 \\
& \frac{\partial u_{x}}{\partial z}=\frac{\partial u_{y}}{\partial z}=\frac{\partial k}{\partial z}=\frac{\partial \varepsilon}{\partial z}=u_{x}=0
\end{aligned}
$$

(3) On insertion water gap exit section, Eq.10 must be satisfied.

$$
\frac{\partial u_{x}}{\partial z}=\frac{\partial u_{y}}{\partial z}=\frac{\partial u_{z}}{\partial z}=\frac{\partial k}{\partial z}=\frac{\partial \varepsilon}{\partial z}=0
$$

(4) Boundary conditions treatment on crystallizer inner wall surface

Adopting wall surface function method contains three main parts. Inside nodes adjacent to first wall surface were laid in turbulence area. Any nodes were laid in viscosity surface layer. High Reynolds number $k-\varepsilon$ model was adopted on turbulence flow core.

\section{Confirmation of draw blank velocity}

Draw blank velocity is on the premise of obtaining good metallurgy quality, safe continuous casting process and high productive capacity continuous caster. Follow factors should be considered on confirming draw blank velocity. 
The computation of theory draw blank velocity maximum is shown in Eq.11 .

$$
v_{\max }=\left(\frac{k_{m}}{\delta_{\min }}\right)^{2} \times L_{m} .
$$

Among above equation, $\delta$ is crystallizer exit blank shell thickness, whose unit is millimeter. $k_{m}$ is solidification coefficient in crystallizer. $L_{m}$ is crystallizer effective length.

\section{Numerical simulation of steel fluid flow in crystallizer \\ Basic hypothesis of linking model and simplified model}

Basic hypothesis of linking model were as follows:

(1) Continuous casting process was regarded as steady state process.

(2)Steel fluid flow was regarded as incompressible Newtonian fluid flow. High Reynolds number $k-\varepsilon$ model was adopted on turbulence effect simulation.

(3) Solid-State Phase Transformation was ignored.

(4) Fluid state density and solid state density were regarded as constant.The simplified steel fluid model in crystallizer is shown in Fig.2.

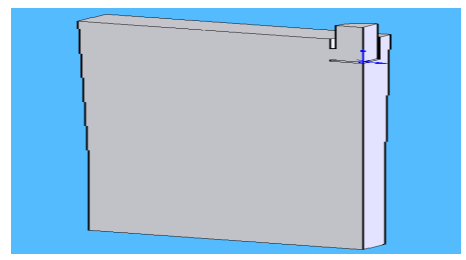

Fig.2 The simplified steel fluid model in crystallizer

\section{Influence factors analysis of steel fluid flow field in crystallizer}

ANSYS CFX can well simulate turbulence flow in fusion area by adopting ozeny-Carman equation and considering the special situation of turbulence attenuation in fusion area. ${ }^{[4]}$ The turbulence characteristic curve under reasonable flow field was shown in fig.3. Among fig.3, Red line is residual error curve of steel fluid flow. Green line is turbulence curve. Fig. 3 shows that turbulence formation curve is unsteady at initial teeming period. While, turbulence formation curve tends to steady along with time addition.

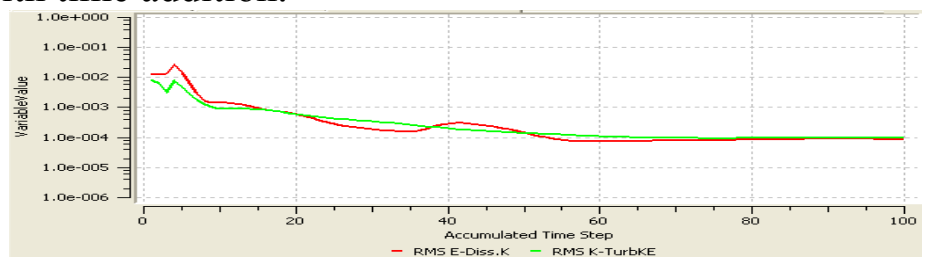

Fig.3 The steel fluid turbulence characteristic curve

The draw blank velocity was influenced by types of steel, blank section, middle steel bag capability, fluid surface height and steel fluid temperature ${ }^{[3]}$.For adjustment convenience, draw blank velocity sets to $0.1 \mathrm{~m} / \mathrm{min}$ every gear or $0.1 \mathrm{~m} / \mathrm{min}$ to $0.2 \mathrm{~m} / \mathrm{min}$. The steel fluid velocity vector diagram and velocity diagram under different draw blank velocity namely $1.4 \mathrm{~m} / \mathrm{min}, 1.6$ $\mathrm{m} / \mathrm{min}, 1.8 \mathrm{~m} / \mathrm{min}$ and $2.0 \mathrm{~m} / \mathrm{min}$ in crystallizer were shown in (a), (b), (c) and (d) of fig.4 and fig.5 respectively.

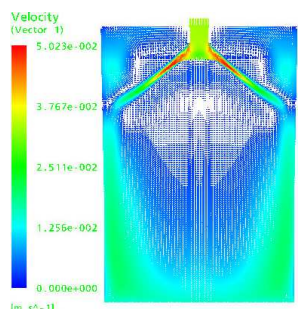

(a) $1.4 \mathrm{~m} / \mathrm{min}$

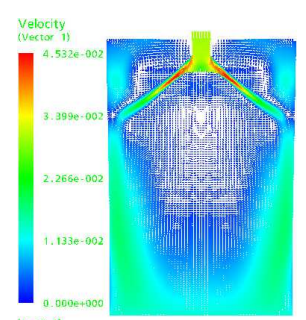

(b) $1.6 \mathrm{~m} / \mathrm{min}$

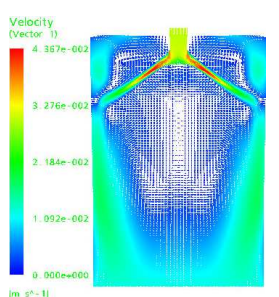

(c) $1.8 \mathrm{~m} / \mathrm{min}$

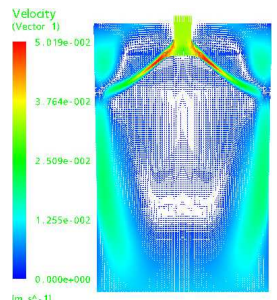

(d) $2.0 \mathrm{~m} / \mathrm{min}$

Fig.4 The steel fluid velocity vector diagram under different draw blank velocity 


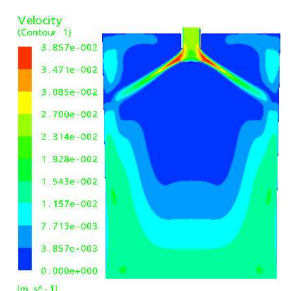

(a) $1.4 \mathrm{~m} / \mathrm{min}$

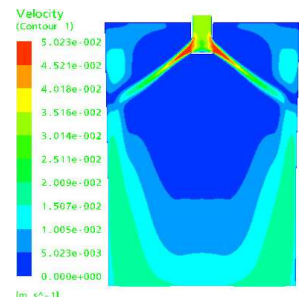

(b) $1.6 \mathrm{~m} / \mathrm{min}$

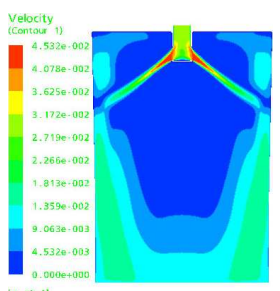

(c) $1.8 \mathrm{~m} / \mathrm{min}$

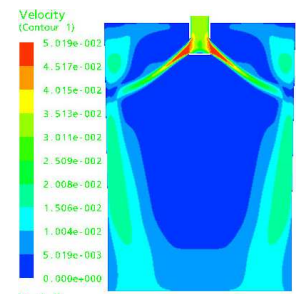

(d) $2.0 \mathrm{~m} / \mathrm{min}$

Fig. 5 The steel fluid velocity diagram under different draw blank velocity

Fig. 4 and fig. 5 show that the influence of draw blank velocity change on upper back flow field is small. But the influence of draw blank velocity on under back flow field can not be ignored. This phenomenon is harmful to blank shell formation on crystallizer bottom, which should cause draw blank leaking steel accident easily. The difference of flow field distribution is small between draw blank velocity under $1.6 \mathrm{~m} / \mathrm{min}$ and $1.8 \mathrm{~m} / \mathrm{min}$. But the flow field distribution under $1.8 \mathrm{~m} / \mathrm{min}$ is more reasonable. Under this draw blank velocity, dregs immixture can be avoided, impurity is easy float upward ${ }^{[5]}$. The increasement of draw blank velocity can also cause the increasement of steel scouring velocity on narrow surface. It can be seen from flow field distribution that draw blank velocity under $1.8 \mathrm{~m} / \mathrm{min}$ can increase productivity and ensure production safety.

\section{Conclusions}

(1) It can be seen from turbulence model curve that steel fluid flow tends to steady gradually in crystallizer along with teeming time addition, which is benefit to uniform blank shell formation.

(2) By simulation computation under different draw blank velocity, it was found that draw blank velocity affects on crystallization quality and production efficiency. When immersion water gap insertion depth and incline angle is fixed, the flow field in crystallizer is the best under draw blank velocity $1.8 \mathrm{~m} / \mathrm{min}$. The numerical simulation results are coincide with practical production data. So, through this research, blank produce can be raised effectively under the base of assurance production safety.

\section{References}

[1] Jun Shi, Xingyuan Zhu, Three-dimensional flow field and temperature field finite element analysis of blank crystallizer. Wuhan University of Science and Technology,Wuhan,2007.

[2] Yazhen Wang, Yan Zhang, Technology and equipment of continuous teeming steel, Metallurgical Industry Press,Beijing,2007.

[3] Lei Xu, Huixin Luo, numerical simulation based on ANSYS ICEM CFD and CFX, Wuhan University of Science and Technology, 2008.

[4] Jinzhu Zhang, Guoping Pan , Zhaolin Yang,Thin slab casting equipment and production technology,Metallurgical Industry Press,Bei Jing, 2007.

[5] Yang H L, Zhao L G, et al. Mathematical simulation on coupled flow, heat and solute transport in slab continuous casting process. Metallurgical and Materials B, 1998, 29B(12): $1345 \sim 1355$ 